\title{
Laboratório de Ensino e Pesquisa em Ciências Sociais (LEPCS): articulando ensino e extensão, da educação básica à licenciatura, em um colégio de aplicação
}

Guilherme Nogueira de Souza * Rodrigo de Souza Pain ${ }^{* *}$

\begin{abstract}
Resumo:
O presente trabalho pretende analisar a estrutura e o funcionamento do Laboratório de Ensino e Pesquisa em Ciências Sociais (LEPCS), um projeto de extensão desenvolvido no Instituto de Aplicação Fernando Rodrigues da Silveira (CAp) da Universidade do Estado do Rio de Janeiro (UERJ). Vinculado ao Departamento de Ciências Humanas e Filosofia (DCHF/CAp/UERJ), o laboratório constitui-se de um coletivo voltado à formação curricular e extracurricular de estudantes de licenciatura em Ciências Sociais, além de contribuir para formação continuada de professores de Sociologia inseridos na educação básica. Com ações, distintas, porém integradas, o LEPCS tem contribuído para a formação de estudantes e futuros professores, colocando-se como ponto de contato entre a universidade e a educação básica.
\end{abstract}

\section{Palavras-chave:}

CAp-UERJ. Extensão. Ensino. Política pública. Sociologia.

\section{Resumen:}

Este trabajo tiene como objetivo analizar la estructura y el funcionamiento del Laboratorio de Enseñanza e Investigación en Ciencias Sociales (LEPCS), un proyecto de ampliación desarrollado en el Instituto de Aplicaciones Fernando Rodrigues da Silveira (CAp) de la Universidad Estatal de Río de Janeiro (UERJ). Vinculado al Departamento de Ciencias Humanas y Filosofía (DCHF/CAp/UERJ), el laboratorio es un colectivo centrado en la formación curricular y extracurricular de estudiantes de grado en Ciencias Sociales, además de contribuir a la formación continua de profesores de sociología insertados en la Educación Básica. Con acciones distintas pero integradas, LEPCS ha contribuido a la formación de estudiantes y futuros profesores, situándose como un punto de contacto entre la universidad y la Educación Básica.

\section{Palabras-clave:}

CAp-UERJ. Extensión. Enseñanza. Política pública. Sociología.

\footnotetext{
* Doutor em Ciências Sociais, professor adjunto de Sociologia no Departamento de Ciências Humanas e Filosofia (DCHF), do Instituto de Aplicação Fernando Rodrigues da Silveira (CAp), da Universidade do Estado do Rio de Janeiro (UERJ). E-mail: voluti@gmail.com. ORCID iD: https://orcid.org/0000-0002-0574-7782.

** Doutor em Ciências Sociais, na área de Desenvolvimento, Agricultura e Sociedade (CPDA-UFRRJ) e Professor Adjunto do Departamento de Ciências Humanas e Filosofia (DCHF) do Instituto de Aplicação Fernando Rodrigues da Silveira da Universidade do Estado do Rio de Janeiro (UERJ). E-mail: rodrigo.pain@gmail.com. ORCID iD: https://orcid.org/0000-0003-2223-5110.
} 


\section{Introdução}

O presente artigo pretende realizar uma reflexão a respeito das potencialidades da extensão, enquanto política institucional, na ampliação das condições gerais de formação inicial e continuada de docentes da educação básica. A análise que aqui se faz é um esforço de estranhamento do familiar (DA MATTA, 1978) e uma tentativa de dar conta do necessário processo de análise dos procedimentos aplicados na formação docente por parte dos professores-formadores e daqueles que, inseridos no ambiente acadêmico tradicional, possuem na construção de vínculos entre a universidade e a sociedade mais - neste caso, vínculos com as escolas públicas de educação básica - sua estratégia de pensar e incidir sobre os dilemas que se impõem ao conjunto da sociedade no que tange aos processos de ensino-aprendizagem e construção de um sistema educacional de qualidade e que atenda às necessidades múltiplas de uma sociedade complexa, diversa e desigual como a sociedade brasileira.

Tendo este intuito como perspectiva, pretende-se analisar o conjunto de ações extensionistas desenvolvidas pelo Laboratório de Ensino e Pesquisa em Ciências (LEPCS). Este laboratório é um projeto de extensão voltado para formação dos futuros docentes na área de Sociologia e áreas correlatas, localizado no interior do Departamento de Ciências Humanas e Filosofia (DCHF) do Instituto de Aplicação Fernando Rodrigues da Silveira (CAp), uma unidade acadêmica da Universidade do Estado do Rio de Janeiro (UERJ).

Para tanto, toma-se como referência teórica, jurídica e político-institucional a Política Nacional de Extensão Universitária (PNEU), desenvolvida pelo Fórum de Pró-reitores de Extensão das Universidades Públicas Brasileiras (FORPROEX), assim como as Diretrizes para as Políticas de Extensão da Educação Superior Brasileira, publicada em 2018 pelo Conselho Nacional de Educação. Estes documentos são tomados como referências para a análise das ações do LEPCS. Entendendo essas ações como parte de uma política pública nacional de extensão universitária, assim como parte de um debate político e acadêmico sobre a formação de professores nas universidades brasileiras diante dos desafios de uma sociedade marcada por diferentes formas de desigualdade e com desafio de superar condições de históricas de desvantagens econômicas, sociais e simbólicas de parcela significativa da sociedade brasileira, especialmente a população pobre e negra, aqueles que correspondem à maioria dos usuários dos serviços públicos de educação nos níveis de Ensino Fundamental e Médio.

As linhas a seguir estão estruturadas em três eixos. O primeiro é uma avaliação da Política Nacional de Extensão Universitária, com sua proposição de cinco eixos de desenvolvimento extensionista, a partir da qual será analisada a atuação do LEPCS enquanto política pública universitária de formação inicial e continuada. O segundo eixo pretende discutir a própria noção de política pública, assumindo que a política nacional de extensão universitária é parte um conjunto amplo de ações do Estado e de seus entes subordinados na prestação de serviços públicos. E, como tal, demandante de condições e parâmetros para avaliação dos resultados. A política extensionista precisa instrumental adequado para avaliar seus efeitos e, eventualmente, corrigir rumos ou reavaliar a alocação de escassos recursos públicos no desenvolvimento de projetos e iniciativas. O terceiro eixo pretende contextualizar e analisar a ação do LEPCS, tendo como perspectiva a especificidade da estrutura formadora de licenciandos da Universidade do Estado do Rio de Janeiro e o contexto do ensino de Sociologia na educação básica.

\section{A extensão como política nacional para as universidades públicas}

O ensino, a pesquisa e a extensão são os pilares históricos de atuação das universidades. Esta tríade não teve desenvolvimento simultâneo ao longa da história das instituições, menos ainda um desenvolvimento linear ou homogêneo. Dentre estas três esferas de ação, a extensão foi a que se desenvolveu mais tardiamente quando comparada à estruturação das práticas institucionais de ensino, consolidadas nas universidades islâmicas ou cristãs medievais, ou de pesquisa, cujo salto constitutivo está vinculado ao século XVII-XVIII e os avanços nas metodologias de pesquisa que comumente chama-se de revolução científica. 
No caso da extensão enquanto política universitária, entretanto, os marcos temporais são mais recentes. Apesar de haver divergências quanto às primeiras práticas de transmissão de conhecimento para além dos muros da universidade, entendidas como a primeira concepção prático-teórica de extensão, há consenso de que o século XIX concebeu as condições necessárias para a estruturação de práticas extensionistas no mundo. Este processo, como aponta Paula (2013), esteve inicialmente centrado em universidades britânicas, tendo se espalhado ainda naquele século por universidades europeias e estadunidenses.

A primeira onda de ações extensionistas na Europa da segunda metade do século XIX se dá no contexto de profundas transformações nas condições sociais e de produção. Transformações estas que levarão para o centro do debate político e acadêmico a situação do nascente operariado urbano e as diversas formas de desigualdade que marcará a emergência dos processos industriais e o adensamento das cidades industriais. É neste contexto que diferentes universidades europeias vão progressivamente adensar suas relações com grupos de trabalhadores através de cursos e atividades culturais (MIRRA, 2009).

As práticas extensionistas atravessam o Atlântico e encontram nos Estados Unidos um terreno fértil para articulação entre a produção do conhecimento universitário e a incorporação do capital tecnológico e humano à administração pública e aos empreendimentos agrícolas e industriais. Diferentemente do ocorre nas práticas de extensão nas universidades europeias, a extensão universitária estadunidense nasce articulada com a ampliação da produtividade do trabalho e do capital. Em ambos os casos, entretanto, o contexto maior é o de consolidação do capitalismo industrial, na cidade e no campo, como tipo fundamental de produção organização social e de produção de riquezas.

A extensão, portanto, assim como o ensino e a pesquisa, nunca esteve deslocada das condições sociais e políticas circundantes. Seja como mecanismo útil para reduzir a confrontação de classe, seja como forma adequada de incorporação dos conhecimentos científicos aos processos produtivos, a estruturação da universidade e, portanto, também da extensão sempre respondeu ao conjunto dos processos histórico-sociais mais amplos, mesmo que se reconheça que as universidades possuem dinâmicas institucionais próprias.

Assim sendo, as primeiras experiências extensionistas são marcadas pela ausência de caráter dialógico e pela posição hierárquica entre a ação de quem sabe sobre quem nada sabe. Isso vale para a relação universidade-trabalhadores ou universidade-processos produtivos. A esta etapa de estruturação das práticas extensionistas, Serrano (2013) chama de "transmissão vertical do conhecimento".

E foi como mecanismo de transmissão vertical do conhecimento que a extensão é formalizada no Brasil. Tendo estruturado o sistema universitário propriamente dito apenas na década de 30 do século XX, sob forte influência dos adeptos da Escola Nova, a extensão na universidade brasileira é formalmente concebida como processo de transmissão de conhecimento da academia para a sociedade, tendo enfoque especial nas chamadas altos interesses nacionais. "Registra-se que, subjacente a essas propostas, estava o objetivo de propagar os ideais de uma classe hegemônica que se instalara no poder" (NOGUEIRA, 2001, p. 59).

Tal caracterização aparece de maneira explícita no Decreto-Lei 19.851 de 1931, como aponta Serrano (2013):

Art. 42. A extensão universitária será efetivada por meio de cursos e conferências de caráter educacional ou utilitário, uns e outras organizados pelos diversos institutos da Universidade, com prévia autorização do Conselho Universitário.

$\$ 1^{\circ}$ Os cursos e conferências, de que trata este artigo, destinam-se principalmente à difusão de conhecimento úteis à vida individual ou coletiva, à solução de problemas sociais ou à propagação de ideias e princípios que salvaguardem os altos interesses nacionais.

$\$ 2^{\circ}$ Estes cursos e conferências poderão ser realizados por qualquer instituto universitário em outros institutos de ensino técnico ou superior, de ensino secundário ou primário ou em condições que os façam acessíveis ao grande público.

Art. 109. A extensão universitária destina-se à difusão de conhecimentos, filosóficos, artísticos, literários e científicos, em benefício do aperfeiçoamento individual e coletivo. 
Entretanto, apesar de seu caráter fundamentalmente conservador, concebendo a extensão como mecanismo de transmissão de conhecimentos da universidade para a sociedade, as práticas extensionistas no Brasil serão ressignificadas pelo contexto político e pela militância dos movimentos sociais, especialmente estudantil, implementando aqui um debate sobre o papel da universidade e sua relação com a transformação social. Tal movimento se dá no início do século XX em diferentes países da América Latina e se enraíza no Brasil por volta dos anos 50, como parte dos muitos debates públicos que o pós-guerra e a queda do Estado Novo possibilitaram.

A esse respeito cabe notar as considerações de Paula (2013) sobre a atuação da União Nacional dos Estudantes (UNE) ao debater reforma universitária como parte das chamadas Reformas de Base na década de 60 e o lugar da extensão na inserção política da universidade no debate público e em defesa dos grupos socialmente vulneráveis:

\begin{abstract}
A luta pela Reforma Universitária, tal como desenvolvida pela UNE, foi parte de uma progressiva aproximação das lutas estudantis e das lutas gerais pela transformação brasileira num movimento que incluiu tanto o que se chamou aliança operário-estudantil e aliança operário-camponesa, a mobilização dos estudantes nas campanhas de alfabetização de adultos, a partir do método desenvolvido pelo professor pernambucano Paulo Freire, quanto o engajamento nas campanhas sanitárias de erradicação de doenças típicas do mundo rural, conduzidas pelo Departamento Nacional de Endemias Rurais (Dneru), órgão do Ministério da Saúde. [...] Também nos núcleos urbanos a mobilização estudantil buscou aproximar-se das lutas sociais. Foi o que, exemplarmente, se deu com a criação do Centro Popular de Cultura (CPC) da UNE, fundado em 1961 que, mediante a literatura, o teatro, a música e o cinema, sobretudo, buscou levar às favelas e às aglomerações populares o esclarecimento, a denúncia, o protesto, a propaganda de uma nova sociedade, que era possível ser construída. (PAULA, 2013, p. 15).
\end{abstract}

Este período de estruturação das ações extensionistas entre pós-guerra e golpe civil-militar de 1964 foi profundamente influenciado pelas concepções educacionais de Paulo Freire, como aponta Serrano (2013). Nele subverte-se a dinâmica unidirecional das práticas de extensão e insere-se a universidade e seus quadros nas dinâmicas sociais mais variadas, não somente para transmitir conhecimentos, mas para elaborar conhecimentos de maneira partilhada e dialógica, atuando sobre os problemas das comunidades em parceira com as comunidades e não mais sobre as comunidades. A proposta de alfabetização freiriana é o exemplo mais acabado de uma prática de extensão que se tornará referência de praxis e teoria para os anos seguintes, a despeito dos impactos que o golpe civil-militar de 1964, do Ato Institucional no 5 , de 13 de dezembro de 1968, e da reforma universitária também de 1968 terão sobre as instituições acadêmicas brasileiras.

No Brasil, as concepções de Freire, um proscrito oficialmente, eram refuncionalizadas, possibilitando seus seguidores agirem de acordo com suas orientações, sem usarem os termos que ele usava. No Ministério da Educação, o grupo que ocupava a Coordenação das atividades de extensão - CODAE — tinha Freire como referência central, o que pode ser mais bem evidenciadona análise do Plano de Ação lançado em 1973. Falava-se em realimentação, mão dupla, retroalimentação e outras terminologias similares que, na realidade, propiciaram a incorporação do sentido de comunicação ao extensionismo. (ROCHA; GURGEL, 2001, p. 22 apud SERRANO, 2013).

A influência de Paulo Freire nas políticas de extensão das universidades brasileiras se expressa no processo de abertura política e redemocratização após a Lei 6.683 de 1979, chamada Lei da Anistia, sancionada pelo Presidente João Baptista Figueiredo (1918-1999), após uma ampla mobilização social, ainda durante a ditadura civil-militar. A criação do Fórum de Pró-reitores de Extensão das Universidades Públicas Brasileiras (FORPROEX), em 1987, é parte deste processo de abertura política e ampliação da vida cívica.

O FORPROEX é uma entidade constituída pelo conjunto dos pró-reitores de extensão e titulares de órgãos de mesma função nas instituições públicas de Ensino Superior. A organização tem por diretriz a articulação e definição de políticas universitárias de extensão que tenha por objetivo incidir sobre realidade 
social circundante às instituições com o intuito de auxiliar na transformação social e na efetivação plena da cidadania através dos recursos institucionais das instituições de formação acadêmica. Tendo por princípio, portanto, a ação sobre o mundo para além dos muros da universidade, o FORPROEX está assentado em cinco pilares de desenvolvimento ${ }^{1}$ :

a) Propor políticas e diretrizes básicas que permitam a institucionalização, a articulação e o fortalecimento de ações comuns das Pró-reitoras de Extensão e órgãos congêneres das Instituições de Ensino Superior Públicas Brasileiras;

b) Manter articulação permanente com representações dos Dirigentes de Instituições de Educação Superior, visando encaminhamento das questões referentes às proposições do Fórum de Pró-Reitores de Extensão das Universidades Públicas Brasileiras;

c) Manter articulação permanente com os demais Fóruns de Pró-Reitores, com o objetivo de desenvolver ações conjuntas que visem à real integração da prática acadêmica;

d) Manter articulação permanente com instituições da sociedade civil, do setor produtivo e dos poderes constituídos, com vistas à constante ampliação da inserção social das Universidades Públicas;

e) Incentivar o desenvolvimento da informação, avaliação, gestão e divulgação das ações de extensão realizadas pelas Instituições de Ensino Superior Públicas Brasileiras.

Atualmente o Fórum é constituído por 145 instituições públicas de Ensino Superior, sendo 94 instituições federais - entre universidades, institutos e centros -, 44 instituições estaduais e 7 instituições municipais, espalhadas por todos os territórios da federação. Na tentativa de produzir uma orientação geral para as ações extensionistas, o FORPROEX iniciou, ainda em 1999, a produção de uma série de documentos que dessem sustentação a uma política universitária robusta de extensão, na tentativa de ampliar os limites de atuação da universidade pública e colocá-la em diálogo com as comunidades avizinhadas e com as demandas sociais, políticas, sanitárias, ambientais e educacionais que não se restringiam aos processos de formação tradicional ofertados pelos cursos de graduação universitária e pós-graduação. A estruturação e consolidação das políticas de extensão intentavam ampliar o foco de ação da universidade e o impacto dos recursos técnicos, científicos e culturais nas comunidades às quais as instituições estão inseridas.

A centralidade do FORPROEX no caso brasileiro se dá pelo papel da instituição de produzir um corpo teórico propositivo para a construção e análise da extensão nas universidades. Este corpo se consolida na Política Nacional de Extensão, publicada em 2012, mas produto de acúmulos da instituição desde 1999 (FORPROEX, 2012). "A Extensão Universitária, sob o princípio constitucional da indissociabilidade entre ensino, pesquisa e extensão, é um processo interdisciplinar, educativo, cultural, científico e político que promove a interação transformadora entre Universidade e outros setores da sociedade" (FORPROEX, 2012, p. 28).

A referência acima é a conceituação de extensão universitária que dá sustentação à essas linhas. Nela, a extensão é concebida como atividade acadêmica por excelência, parte da realização da função social, legal e institucional da universidade pública, assentada numa concepção dialógica com o mundo na perspectiva de realização dos anseios democráticos e republicanos que deram a tônica da Constituição de 1988.

A concretização desta perspectiva conceitual sobre a extensão universitária se desdobra em cinco diretrizes centrais, como nos aponta Nogueira (2000). Essas diretrizes são: 1) Interação dialógica; 2) Interdisciplinaridade e Interprofissionalidade; 3) Indissociabilidade ensino-pesquisa-extensão; 4) Impacto na formação do estudante; 5) Impacto na transformação social.

Por "interação dialógica" entende-se uma concepção de ação extensionista na qual a universidade interage com o mundo, afetando-o e sendo afetada, construindo conhecimento "com" e não somente "para". Essa perspectiva propõe romper com um modelo de extensão unilateral e hierárquico no qual a centralidade

1. Disponível em: https://xn--extenso-2wa.ufrj.br/index.php/forum-de-pro-reitores-de-extensao. Acesso em: 15 abr. 2020. 
está no conhecimento pronto a ser transmitido de "quem sabe", a universidade e seus quadros qualificados, para "quem não sabe", todo o mundo circundante, e abre possibilidades de valorizar diferentes formas e níveis de conhecimento na construção de soluções para os desafios do mundo.

Essa construção dialógica com o mundo precisa compreender a complexidade dos fenômenos sociais que nos cercam. E, neste sentido, assumir um olhar interdisciplinar e interprofissional no planejamento, execução e avaliação das ações extensionistas. "O suposto dessa diretriz é que a combinação de especialização e visão holísticas pode ser materializada pela interação de modelos, conceitos e metodologias oriundos de várias disciplinas e áreas do conhecimento, assim como pela construção de alianças intersetoriais, interorganizacionais e interprofissionais" (FORPROEX, 2012, p. 32).

A diretriz Indissociabilidade Ensino-Pesquisa-Extensão reafirma a extensão universitária como processo acadêmico. O suposto é que as ações de extensão adquirem maior efetividade se estiverem vinculadas ao processo de formação, através do ensino, e de geração de conhecimento, através da pesquisa. Por um lado, essa concepção possibilita ampliar a formação dos estudantes, colocando-os precocemente, mas sob supervisão qualificada, diante dos problemas do mundo circundante, muitos dos quais se depararão uma vez formados. Por outro lado, a articulação entre pesquisa e extensão demanda uma reinvenção da própria metodologia de pesquisa uma vez os desafios teóricos se defrontam com as questões do mundo. Em ambos os casos, a extensão articulada com outras facetas da função social da universidade aponta para a qualificação da política pública, seja no âmbito da formação, seja no âmbito da construção e aplicação dos conhecimentos por parte das estruturas acadêmicas.

Como dito anteriormente, "as atividades de Extensão Universitária constituem aportes decisivos à formação do estudante, seja pela ampliação do universo de referência que ensejam, seja pelo contato direto com as grandes questões contemporâneas que possibilitam” (FORPROEX, 2012, p. 34). Entretanto, para tal, três condições são essenciais: 1) É preciso que haja orientação adequada por parte de professores de modo a realizar a potência formativa da experiência extensionista; 2) Os objetivos da ação e as habilidades necessárias e/ou almejadas devem ser conhecidos de modo a orientar a ação e, posteriormente, sua avaliação; 3) É preciso uma metodologia participativa que possibilite a avaliação da ação e a avaliação dos atores no desenvolvimento da ação.

Por fim, a diretriz Impacto e Transformação Social aponta para a centralidade da extensão universitária como o mecanismo inter-relacional entre a academia e outros setores da sociedade, visando a transformação social em favor dos interesses e necessidades da maioria da população e realização do desenvolvimento social através do aprimoramento das políticas públicas.

Com essa diretriz, espera-se configurar, nas ações extensionistas, as seguintes características: (i) privilegiamento de questões sobre as quais atuar, sem desconsideração da complexidade e diversidade da realidade social; (ii) abrangência, de forma que a ação, ou um conjunto de ações, possa ser suficiente para oferecer contribuições relevantes para a transformação da área, setor ou comunidade sobre os quais incide; (iii) efetividade na solução do problema. (FORPROEX, 2012, p. 36).

\section{Extensão enquanto política pública e o desafio do monitoramento e avaliação}

Com o advento da Constituição de 1988, o modelo preponderante de políticas sociais adotadas no país possuía forte caráter universalista. Por políticas públicas ou sociais de caráter universalista pode-se entender um conjunto de intervenções do Estado na sociedade de civil de modo a garantir a prestação de serviços e o acesso a bens sociais ou públicos de maneira irrestrita ao conjunto dos cidadãos legalmente reconhecidos ou moradores submetidos a uma determinada autoridade estatal. A universidade, apesar de processo restritivo de acesso aos cursos de graduação e pós-graduação, tem forte papel enquanto prestador 
de serviços públicos de diferentes ordens. A extensão é parte dessa estrutura com potencialidade de desenvolvimento de política pública, tanto de caráter universalista, como de caráter focalizado como se verá adiante.

Paixão (2006), ao discutir o sistema de cotas raciais, nos recorda que as políticas de caráter universalista foram amplamente empregadas na Europa ocidental em decorrência da consolidação do Estado de bem-estar social nos anos que sucederam ao fim da $2^{\text {a }}$ Guerra Mundial. Assim, como decorrência de uma determinada noção de justiça social, o Estado tornou-se mais do que fiador dos contratos celebrados no mercado, mas passou a intervir neste mercado, consolidando uma noção de bens sociais que deveriam estar acessíveis ao conjunto dos cidadãos, como acesso à educação, saúde, transporte ou moradia independentemente da situação do indivíduo frente ao mercado. Logo, a consolidação das políticas universalistas, criou mecanismos que reduziram significativamente as desigualdades. Por outro lado, aponta Paixão (2006) que a adoção deste modelo de política social enfrenta duas grandes limitações fundamentais:

O primeiro limite da proposta universalista está no fato de que, em nome da adoção de uma visão não discriminatória, muitas vezes tal orientação não presta a devida atenção ao combate às efetivas discriminações existentes na sociedade civil. No caso de se verificarem grandes abismos sociais entre os distintos grupos da população, o tratamento indiferenciado aos diversos segmentos pode tão-somente servir para a consolidação de antigas disparidades. [...] O segundo limite do modelo universalista associa-se ao fato de que nem mesmo na Europa Ocidental tal modelo logrou efetivamente se universalizar, antes beneficiando as pessoas que nasceram em uma determinada localidade ou país, muitas vezes deixando de fora os imigrantes e minorias raciais, étnicas, religiosas que não pertencem ao grupo dominante da sociedade. (PAIXÃO, 2006, p. 130-131)

Por outro lado, pode-se entender por políticas focais, aquelas cujo público alvo não se confunde com o conjunto da comunidade, mas apenas uma parcela específica selecionada segundo critérios previamente definidos. Frente aos debates sobre redução das desigualdades e tendo em vista a prioridade que o elemento renda assume neste debate, muitos dos defensores das políticas sociais focais operam com a percepção de caberia ao Estado elaborar políticas públicas para aqueles que estão à margem do acesso aos bens e serviços via mercado, priorizando, portanto, os mais pobres ou marginalizados pelo mercado ao acesso a bens considerados elementares. Assim sendo, como nos aponta Höfling (2001), as políticas focais estariam voltadas para a superação de um modelo de organização e distribuição geral da riqueza, mas para ajustes marginais para aqueles que, por incapacidade ou temerárias escolhas biográficas não se mostrassem aptos aproveitarem progresso social produzido dentro de uma sociedade de mercado. Esta perspectiva é comumente chamada de "residualista".

Ao se debruçar sobre as políticas focais, Paixão (2006) aponta que estas também possuiriam alguns importantes inconvenientes, dentre estes destaca-se o fato de que a proposta focalista "tende a reduzir a pressão para processos distributivos no interior do país" (PAIXÃO, 2006, p. 131). Ademais, por conta de sua vinculação a uma perspectiva de mercado, a proposta focalista tenderia a reduzir o que o autor chama de solidariedade social tendo em vista que parcelas expressivas da população obteriam os serviços não a partir de políticas públicas universais, mas através do mercado.

Segundo Kerstenetzky (2006), entretanto, há mais complexidade na suposta dualidade entre políticas sociais universais e políticas sociais focais. Para a autora, as duas modalidades estão vinculadas a concepções distintas de justiça social e de atuação do Estado. Mas, ao mesmo tempo, seria possível a articulação entre as duas modalidades.

Às vezes, a busca do foco correto pode resultar no formato contraintuitivo de incondicionalidade, como quando se atinge melhor os mais necessitados estendendo-se um benefício a todos dentro de um determinado território, supostamente razoavelmente homogêneo, e não apenas aos mais necessitados (em que se poupam, por exemplo, os custos de monitoramento). Neste caso específico, a melhor forma de encontrar o foco é "universalizar". (KERSTENETZKY, 2006, p. 570). 
Ademais, aponta Kerstenetzky (2006), a existência de uma noção republicana de política social focal na qual o exercício pleno da cidadania demandaria a manutenção de políticas sociais universalistas, por um lado, e a criação de políticas focais de maneira a reduzir as desvantagens acumuladas de grupos populacionais. A existência de políticas universalistas formais não é garantia de redução real dos níveis de desigualdade, como já foi apontado acima. Assim sendo, existe a possibilidade justaposição e/ou composição entre políticas universalistas e políticas focalistas visando a realização plena da cidadania, estabelecendo o atendimento preferencial ou focado a grupos que, mesmo diante de sistemas universais de acesso a bens sociais e serviços, não usufruem destes como o restante da sociedade.

Há ainda um segundo sentido possível de focalização, como ação reparatória, necessária para restituir a grupos sociais o acesso efetivo a direitos universais formalmente iguais - acesso que teria sido perdido como resultado de injustiças passadas, em virtude, por exemplo, de desiguais oportunidades de realização de gerações passadas que se transmitiram às presentes na perpetuação da desigualdade de recursos e capacidades. Sem a ação/política/programa, focalizados nesses grupos, aqueles direitos são letra morta ou se cumprirão apenas em um horizonte temporal muito distante.

Cabe frisar que esta conjugação de perfis de políticas sociais permite romper também com a dualidade estado $\mathrm{x}$ mercado em que as políticas universais - consolidadas junto ao estado social keynesiano - e políticas focais - que emergiram junto com crise fiscal dos Estados sociais-democratas e o retorno da centralidade do liberalismo - corresponderiam respectivamente a um e outro de maneira simplista.

A Constituição de 1988 elencou uma série de serviços públicos cujo financiamento deve ser progressivo e com caráter de política de Estado, visando a manutenção de serviços básicos essenciais e se constante financiamento, independentemente do governo do momento (THEODORO; DELGADO, 2003, p. 4-5). Mas, ao mesmo tempo, é possível conciliar a manutenção e necessária ampliação das políticas universalistas com a implementação de políticas focalistas de forma a acelerar processos de inclusão social de grupos minoritários específicos que somente se dariam em tempos muito distantes a depender apenas da implementação das políticas públicas de caráter universal sem nenhuma modalidade ação focal voltada para públicos específicos, historicamente alijados ou sub-representados como usuários de algum serviço público.

Neste sentido, a extensão universitária é o braço da universidade com maior possibilidade de prestar serviços públicos, desenvolvendo política pública tanto de caráter universal — algo até momento impossível no que tange ao acesso aos cursos de graduação e pós-graduação tendo em vista às exigências de concurso - quanto de caráter focalista, dando ênfase a comunidades e atores específicos que estão nas cercanias da universidade, tornando-os usuários de serviços da universidade para além do ensino e/ou da pesquisa. Por mais que, como já visto anteriormente, a extensão universitária está intimamente articulada com os demais eixos de desenvolvimento e atuação da universidade.

Para que a extensão possa ser exitosa enquanto política pública voltada para a comunidade externa à universidade é preciso que ela seja concebida de maneira adequada, avaliada periodicamente e reestruturada à medida que desenvolve a prática extensionista. A extensão possui uma dinâmica própria e dada a sua multiplicidade potencial exige que cada projeto desenvolva seus mecanismos de monitoramento e avaliação.

Monitoramento, por sua vez, "diz respeito à observação regular e sistemática do desenvolvimento das atividades, do uso dos recursos e da produção de resultados, comparando-os com o planejamento inicial" (MARTINS et al., 2008). O monitoramento diz respeito a construção processual de dados que sirvam aos processos de avaliação da política pública implementada de forma que seja possível avaliar em determinado período as transformações produzidas e se elas se adequam ao rumo planejado quando do início da política pública. Se, por um lado, a avaliação diz respeito a um conjunto de valores que orientam e definem uma opção por uma política pública; por outro, o monitoramento subsidia os processos de avaliação com dados necessários para que se possa acompanhar a efetividade, eficácia e desempenho da política social. Assim sendo, o monitoramento "deve produzir informações e dados confiáveis para subsidiar a análise da razão de eventuais desvios, assim como, das decisões de revisão do plano” (MARTINS et al., 2008).

A avaliação de política pública pode ser entendida como “julgar a importância de uma ação em relação a um determinado referencial valorativo e aceito como tal pelos sujeitos que avaliam.Avaliar, então, 
não significa apenas medir, mas julgar a partir de um referencial de valores" (MARTINS et al., 2008). Assim sendo, "a avaliação tem o papel de analisar criticamente o andamento do serviço/projeto, segundo seus objetivos, tendo por base as informações produzidas pelo monitoramento", prosseguem Martins et al. (2008).

"O propósito da avaliação é guiar os tomadores de decisão, orientando-os quanto à continuidade, necessidade de correções ou mesmo suspensão de uma determinada política ou programa" (COSTA; CASTANHAR, 2003, p. 972). Com isso os autores apontam que o processo de avaliação de uma política pública não é mero exercício diletante. A avaliação e monitoramento possuem a função de fornecer ao conjunto dos gestores responsáveis pelo desenvolvimento da política informações de relevância que auxiliem na correção de rumos, na mudança de estratégia e na resolução de problemas seja durante a execução, seja em fases posteriores ou em desdobramentos da política pública.

Ramos e Schabbach (2012) apontam que a preocupação com a avaliação e monitoramento de políticas públicas no Brasil ainda é relativamente recente. Se no plano internacional esta perspectiva começa a se desenvolver a partir dos anos 60, especialmente no Estados Unidos, no Brasil, o marco para esta nova orientação da ação estatal está na reforma administrativa de 1998, através da Emenda Constitucional 19. Ademais, segundo as autoras,

[a]lém da preocupação com a efetividade, podem ser citadas outras razões que fomentaram a demanda por avaliações em nosso país, especialmente a partir dos anos 1990: a crise fiscal que diminuiu a capacidade de gasto dos governos e aumentou a pressão por maior eficiência; o fim do processo inflacionário, que reduziu as receitas financeiras dos governos e expôs os problemas das finanças públicas; o aprofundamento da democracia, que trouxe novos atores sociais e reivindicações aos governos; a longa crise econômica brasileira que aumentou a desigualdade social e a busca por programas sociais públicos; a desestruturação da função de planejamento, que deixou os governantes sem elementos de informação e avaliação; a redução da ajuda externa e a pressão dos organismos internacionais de fomento pela aferição dos resultados dos programas sociais por eles financiados. (RAMOS; SCHABBACH, 2012, p. 1274).

\section{O LEPCS no contexto da atuação do CAp-UERJ}

Nascidos como campo para a prática didática dos futuros docentes, os ginásios experimentais ou colégios de aplicação desempenharam o papel incontornável na formação docente entre os anos de 1946 e 1968, sob a supervisão das Faculdades de Filosofia, Ciências e Letras. Com o desmonte destas instituições e o fim da obrigatoriedade de manutenção dos colégios de aplicação por parte das universidades, o arcabouço institucional sob os quais os ginásios existiam desapareceu, alterando radicalmente a função destas instituições no interior das universidades. Alguns, inclusive, foram fechados neste processo.

No caso do CAp-UERJ, entretanto, a sua obrigatoriedade como campo de estágio para as licenciaturas permaneceu a despeito das transformações legais e da perda de protagonismo dos ginásios experimentais no processo de formação docente. No entanto, apesar da autonomia administrativa e financeira conquistada ainda 1967 e da permanência como campo obrigatório de estágio, somente na década de 90 o colégio é instado, no contexto da aprovação da Lei de Diretrizes e Bases da Educação Nacional (Lei 9394/96), a apresentar um ambicioso projeto de reforma da licenciatura na universidade, ao mesmo tempo em que demandava uma rediscussão sobre sua posição frente à estrutura universitária. Apesar das reformas organizacionais que deram estrutura departamental ao colégio em 1986/1987, o CAp ainda não dispunha do status de unidade acadêmica. Neste contexto de debate sobre a educação e o lugar do CAp na formação docente, o colégio consegue alteração do seu status institucional ao ser transformado de unidade acadêmica. Apesar da tramitação longa, entre 1997 e o início dos anos 2000, a unidade deixa de ser colégio de aplicação para tornar-se instituto de aplicação. O campo obrigatório de estágio dá lugar um modelo de formação tripartite para todos os cursos de licenciatura da Universidade do Estado do Rio de Janeiro em seu campus principal, localizado no bairro do Maracanã. Neste modelo, conforme a Deliberação 021 de 2005, a Faculdade de Educação, os 
Institutos-base e CAp partilham a oferta de disciplinas obrigatórias teóricas, disciplinas eletivas, de estágio e de prática de ensino (UERJ, 2005).

O CAp-UERJ, portanto, é, ao mesmo tempo uma escola, que atende a 1100 alunos da educação básica, aproximadamente, do $1^{\circ}$ ano do Ensino Fundamental ao $3^{\circ}$ ano do Ensino Médio; como também é uma unidade formadora de licenciandos das mais diferentes áreas. Atendendo a centenas de estudantes de graduação em mais de 14 cursos de licenciatura. Isso sem considerar os variados projetos de pesquisa que são desenvolvidos na unidade e a existência do Programa de Pós-graduação em Ensino de Educação básica (PPGEB) sediado na unidade.

O atendimento disciplinar aos estudantes da educação básica e graduação é feito pelos departamentos do CAp. Conforme o Projeto político-pedagógico (UERJ, 2013), o CAp é constituído porseis departamentos interdisciplinares - a saber, Departamento de Ensino Fundamental (DEF), Departamento de Educação Física e Artes (DEFA), Departamento de Línguas e Literatura (DLL), Departamento de Matemática e Desenho (DMD), Departamento de Ciências da Natureza (DCN) e Departamento de Ciências Humanas e Filosofia (DCHF) - , compostos por diferentes coordenações de área. O DCHF conta com mais de 30 professores, distribuídos nas coordenações de Filosofia, Geografia, História e Sociologia. Cada coordenação atende aos licenciandos dos respectivos cursos.

O Laboratório de Ensino e Pesquisa em Ciências Sociais (LEPCS) é um coletivo criado em 2017, voltado para a formação curricular e extracurricular de estudantes de licenciatura em Ciências Sociais e áreas afins de diferentes instituições de ensino, além de contribuir para formação continuada de professores de Sociologia inseridos na educação básica. O laboratório está vinculado à Coordenação de Sociologia do Departamento de Ciências Humanas e Filosofia (DCHF) do Instituto de Aplicação Fernando Rodrigues da Silveira (CAp-UERJ) e, na perspectiva da vocação histórica deste instituto para formação de docentes, pretende ampliar o foco de ação de maneira a contribuir para diversificação na formação dos licenciandos, assim como para aformação continuada de docentes que já se encontram em sala de aula. Ademais, o laboratório pretende contribuir para o trabalho do professor de Sociologia no Ensino Médio através da pesquisa eelaboração de materiais didáticos que venham a facilitar o trabalhodocente. Por fim, o laboratório se propõe a ser um espaço dinâmico para professores, estudantes e pesquisadores terem acesso a um conjunto amplo de materiais voltados para o ensino de Sociologia na educação básica. Pretende-se que legislação, artigos, teses, dissertações, materiais didáticos, conteúdos programáticos, experiências didáticas estejam à disposição da comunidade interna eexterna, possibilitando que o LEPCS se transforme em uma importante ferramenta de trabalho na área. Desta forma, o presente projeto pretende ser um braço de ação da universidade para além dos seus muros, focado na formação e aperfeiçoamento de professores do presente e do futuro.

Área do conhecimento com desenvolvimento autônomo recente, as Ciências Sociais (Sociologia, Antropologia e Ciência Política) possuem no Brasil o seu primeiro florescer institucional vinculado aos movimentos de reforma educacional do início do Século XX, especialmente articulado com a reforma da Pedagogia enquanto campo do conhecimento (LIEDKE, 2005). Neste sentido, a Sociologia, antes de ser disciplina da educação básica no Brasil, emerge nas grades dos cursos de Educação Normal visando contribuir para a transformação da pedagogia tradicional de uma educação para crianças e jovens ainda fortemente influenciada pelo catolicismo e com pouca relação com a produção do conhecimento ou mesmo com a incorporação dos conhecimentos mais modernos à época. A influência do Positivismo na reforma de Benjamin Constant (1890) e nas reformas subsequentes dão a tônica e o perfil da contribuição da Sociologia na educação nacional: “[...] questão de moral do cidadão” e de cumprimento de direitos e deveres constitucionais pelos indivíduos para a construção do Estado-Nação [...]” (RÊSES, 2004, p. 7).

A Sociologia se massifica institucionalmente, portanto, já no diálogo na formação de professores. Esse curto período, entre 1901 e 1941, marcou o início da contribuição da Sociologia na formação de docentes e na reflexão a respeito de um projeto de educação e de sociedade. Ademais, neste período a Sociologia vai sendo introduzida em outros ramos da e ducação básica em diferentes regiões do país. Por sua vez, a Sociologia se consolida no Ensino Superior, enquanto área institucional de pesquisa e produção de conhecimento, a partir dos anos 30 como parte de uma demanda social para a formação de quadros capazes de enfrentar os dilemas do Brasil frente a sua elite política, cultural e econômica. O êxito no Ensino Superior, no entanto, 
foi acompanhado por uma profunda intermitência na educação básica. Apesar do ensino de Sociologia ter seu desenvolvimento inicial nos cursos de normalistas, a história da disciplina foi marcada por avanços e retrocessos, entradas e saídas da grade curricular do ensino regular. Esta intermitência impossibilitou a consolidação de uma tradição disciplinar e curricular no ensino de Sociologia para educação básica.

A atuação do LEPCS vincula-se à perspectiva de que suas ações ampliem a qualidade da formação dos licenciandos em Ciências Sociais, assim como de professores de Sociologia e demais profissionais de educação interessados nas suas atividades, lidando diretamente com o desenvolvimento de habilidades e competências indispensáveis à prática docente. A Sociologia é portadora de temas tradicionais, ancoradas por conceitos e teorias, os quais precisam estar presentes no currículo e, consequentemente, em sala de aula. No entanto, por se tratar de uma ciência humana extremamente sensível a um mundo cada vez mais dinâmico do ponto de vista de suas transformações políticas, econômicas e culturais, precisa desenvolver instrumentos de atualização e de releitura do seu objeto, de modo que teoria e prática estejam em constante diálogo. Ao propor a produção e a organização de um conjunto de materiais para a educação básica, assim como a criação de um espaço de pesquisas e debates sobre o ensino de sociologia e a formação de professores, o laboratório propõe a integração entre ensino e pesquisa, além de se apresentar como destaque numa área do conhecimento ainda em vias de legitimação no estado do Rio de Janeiro e no Brasil, haja vista a mencionada intermitência da disciplina nos currículos de nível médio. Na criação desse espaço amplo de construção pedagógica e produção acadêmica, seguindo as recomendações das Orientações Curriculares para o Ensino Médio (OCN), que recomendam o uso deferramentas como a pesquisa, a elaboração de recursos didáticos os mais variados e dinâmicos, e o contato interdisciplinar. Nesse sentido, o LEPCS se propõe a uma dupla função, fundamental para o processo de ensino-aprendizagem: condensar experiências didático-pedagógicas direcionando-as para a utilização em sala de aula, assim como pensar a própria realidade na qual está inserido.

Os objetivos do projeto são: a) Promover a articulação entre universidade e redes e níveis de ensino, atendendo à demanda de formação continuada dos professores; b) Promover a pesquisa acadêmica com temáticas contemporâneas e articuladas às demandas da educação básica; c) Organizar banco de dados das pesquisas realizadas, favorecendo a sua difusão e repercussão, especialmente na consolidação de material didático; d) Promover seminários, eventos e mesas periódicos sobre de temas relacionados ao campo de interesse do laboratório; e) Promover a elaboração, seleção e difusão de materiais didáticos inovadores.

\section{As ações extensionistas do LEPCS na formação docente}

Entre 2017 e 2019, o LEPCS desenvolveu distintas atividades nas seguintes direções: a) Articulação entre universidade e escolas públicas estaduais do Rio de Janeiro, atendendo à demanda de formação continuada dos professores. Nesse sentido, se em 2018 foram feitas 14 atividades em estabelecimentos educacionais de 6 municípios do Estado, em 2019 foram realizadas 17 atividades em 9 colégios distintos, oito deles na capital; b) Promoção de pesquisa acadêmica com temáticascontemporâneas e articuladas às demandas da educação básica: Entre 2018 e 2019, os pesquisadores associados ao LEPCS participaram de diversos eventos acadêmicos e realizaram publicações concernentes aos seus temas de pesquisa e extensão. Cabe destacar participação dos pesquisadores no V CEDUCE², em 2018, e no VI CONEDU ${ }^{3}$, discutindo a produção de material didático e a articulação universidade-escola, além de terem composto a comissão científica de dois congressos acadêmicos em 2019. Também participaram do X SICEA ${ }^{4}$, ocorrido em novembro de 2019 e que discutiu a posição dos CAp's frente às reformas educacionais; c) Acumular dados

\footnotetext{
2. V Colóquio Internacional de Educação, Cidadania e Exclusão, realizado em 2018, na cidade de Niterói, no Rio de Janeiro, entre os dias 28 e 30 de junho.

3. VI Congresso Nacional de Educação, realizado em 2019, na cidade de Fortaleza, no Ceará, entre os dias 24 e 26 de outubro.

4. X Seminário de Institutos, Colégios e Escolas de Aplicação, realizado em 2019, na cidade de Porto Alegre, no Rio Grande do Sul, entre os dias 12 e 14 de novembro.
} 
das pesquisas realizadas, favorecendo a sua difusão e repercussão, especialmente na consolidação de material didático: tendo em vista a ausência de suporte institucional, este objetivo foi alcançado apenas parcialmente; d) Promoção de seminários, eventos e mesas periódicas sobre temas relacionados ao campo de interesse do Laboratório: no primeiro semestre de 2019, o LEPCS organizou, juntamente com o DCHF, a 1a Semana de Formação em Ciências Humanas e Filosofia, com 16 atividades distintas em 4 dias, articulando quase 30 professores e mais de 170 estudantes. Já em novembro de 2019, também articulado ao DCHF, realizou a $1^{a}$ Semana da Consciência Negra do CAp-UERJ, envolvendo toda a unidade acadêmico-escolar. Ademais, o LEPCS realizou diversas palestras e mesas debatendo assuntos educacionais voltados para estudantes do Ensino Médio do CAp-UERJ e alunos da licenciatura em Ciências Sociais da UERJ.

Ao longo deste período foi possível observar: 1) o envolvimento dos estudantes da educação básica em ações que escapam à tradição curricular e utilizam uma linguagem alternativa, o que foi alcançado a partir das palestras e oficinas realizadas em colégios da rede estadual sobre temáticas sociológicas e de interesse do público jovem, inclusive utilizando-se de recursos pedagógicos audiovisuais; 2) a impressão dos estudantes de licenciatura da UERJ na ida aos colégios estaduais, muitas vezes auxiliando nos debates sobre combate aos preconceitos cotidianos (bullying, racismo, homofobia, dentre outros) e também falando sobre suas experiências como alunos cotistas da UERJ, num trabalho de estímulo a que estudantes da rede estadual vislumbrem a universidade como caminho futuro de investimento na educação superior; 3) foram apresentadas propostas articuladas aos direitos humanos em tempos de ameaças à democracia e fortes movimentações conservadoras e reacionárias, o que foi obtido principalmente em palestras realizadas na UERJ, voltadas aos estudantes da licenciatura, sobre temáticas fundamentais do cotidiano escolar, como o enfrentamento das fake news e a valorização das ciências humanas; 4) o laboratório conseguiu ampliar o espaço de formação do licenciando em Ciências Sociais da UERJ, com abordagens multidisciplinares no trato de questões formalmente curriculares e/ou transversais, o que foi estimulado por meio da participação de muitos deles na $1^{a}$ Semana de Formação em Ciências Humanas e Filosofia e no auxílio à execução da $1^{\text {a }}$ Semana da Consciência Negra do CAp-UERJ.

As propostas do LEPCS estão atreladas ao espírito da unidade de origem do Laboratório, o CAp-UERJ, instituição responsável por ensino, estágio, pesquisa e extensão. O Laboratório de Ensino e Pesquisa em Ciências Sociais (LEPCS) constitui-se num coletivo voltado para a formação curricular e extracurricular de estudantes de licenciatura em Ciências Sociais, além de contribuir para formação continuada de professores de Sociologia inseridos na educação básica. É um braço de ação da universidade para além dos seus muros, focado na formação e aperfeiçoamento de professores do presente e do futuro, sempre atentos aos novos conhecimentos que se colocam diante de nós, inclusive no que tange ao uso da tecnologia em sala de aula. $\mathrm{Na}$ criação desse espaço amplo de construção pedagógica e produção acadêmica, também pretende-se seguir as recomendações das Orientações Curriculares para o Ensino Médio (BRASIL, 2006), que indicam o uso de ferramentas como a pesquisa, a elaboração de recursos didáticos os mais variados e dinâmicos, e o contato interdisciplinar. Nesse sentido, o LEPCS se propõe a uma dupla função, fundamental para o processo de ensino-aprendizagem: condensar experiências didático-pedagógicas direcionando-as para a utilização em sala de aula, assim como pensar a própria realidade na qual se está inserido. Ademais, a diretriz metodológica adotada pelo Laboratório se propõe a fazer a mediação entre diferentes grupos que compõem a educação, a extensão e a pesquisa no processo de formação, colocando professores da educação básica, docentes universitários, pesquisadores, estagiários de licenciatura e estudantes da educação básica em contato, o que possibilita uma troca com resultados formativos para todos.

\section{Considerações finais}

O presente trabalho pretendeu analisar as ações do Laboratório de Ensino e Pesquisa em Ciências Sociais a partir da concepção da extensão universitária proposta pelo FORPROEX, e também de algumas perspectivas a respeito das políticas públicas em geral, de maneira a poder refletir sobre a extensão como 
elemento indissociável do ensino e da pesquisa e como parte elementar da ação universitária. Neste sentido, demonstrou-se de que maneira um projeto extensionista voltado para a formação de docentes é capaz de articular múltiplas facetas de uma instituição de vocação tão particular quanto o CAp-UERJ. O caráter híbrido da instituição, a despeito das recentes crises que marcaram a Universidade do Estado do Rio de Janeiro, e suas limitações organizacionais e institucionais criam possibilidades de ampliação da vivência dos licenciandos em um processo mais enriquecido de formação. Essa formação, apesar de apresentar problemas dos mais variados dado a ausência de uma tradição curricular consolidada e ao momento histórico presente, tem a possibilidade de entregar uma experiência rica para os estudantes de diferentes níveis e distintas instituições.

Ao mesmo tempo, o LEPCS foi pensado não somente como projeto de extensão, mas como parte de uma prática de política pública. Entende-se neste trabalho que a extensão precisa ser analisada e monitorada, assim como atuação da universidade, como parte de um complexo teórico que se possa denominar de avaliação de política pública. Essa perspectiva tende a enriquecer o debate e o desenvolvimento das práticas universitárias. E, neste trabalho, fez-se o esforço de articular extensão e política pública. Nessa perspectiva, tomando alguns dos objetivos do LEPCS, percebe-se que alguns elementos ainda carecem de melhor investimento, especialmente no que tange às redes de comunicação e consolidação mecanismos de suporte aos professores que já atuam nas redes educacionais. Ter a perspectiva do que não pode ser realizado no curto período de desenvolvimento do projeto abre a possibilidade de reorganizar os rumos, redefinindo os caminhos.

\section{Referências}

BRASIL. Secretaria de Educação básica. Orientações curriculares para o Ensino Médio. Brasília, DF: MEC/SEB, 2006. p. 239.

COSTA, Frederico da; CASTANHAR, José. Avaliação de programas públicos: desafios conceituais e metodológicos. Revista de Administração Pública, Rio de Janeiro, v. 37, n. 5, p. 969-992, set./out. 2003.

DA MATTA, Roberto. O ofício de etnólogo, ou como ter anthropological blues. Boletim do Museu Nacional: Antropologia, Rio de Janeiro, n. 27, p. 1-12, maio 1978.

HÖFLING. Eloisa de Mattos. Estado e políticas (públicas) sociais. Cadernos Cedes, Campinas, v. 21, n. 55, p. 30-41, nov. 2001.

KERSTENETZKY, Célia Lessa. Políticas sociais: focalização ou universalização? Revista de Economia Política, São Paulo, v. 26, n. 4, p. 564-574, out./dez. 2006. Disponível em: https://centrodeeconomiapolitica.org.br/rep/index.php/ journal/article/view/616/614. Acesso em: 19 maio 2020.

LIEDKE FILHO, Enno Dagoberto. A Sociologia no Brasil: história, teorias e desafios. Sociologias, Porto Alegre, ano 7, n. 14, p. 376-437, jul./dez. 2005.

MARTINS, Maria Lucimar Pereira; SCHIBELSKY, Simoni Michele Oliveira; RIZOTTI, Maria Luiza Amaral; PAULILO, Maria Ângela Silveira. Avaliação em monitoramento nas políticas sociais. Serviço Social em Revista, Londrina, v. 10, n. 2, jan./jul. 2008. Disponível em: http://www.uel.br/revistas/ssrevista/c-v10n2_lucimar.htm. Acesso em: 9 abr. 2020.

MIRRA, Evando. A ciência que sonha e o verso que investiga. São Paulo: Editora Papagaio, 2009.

NOGUEIRA, Maria das Dores Pimentel (org.). Extensão universitária: diretrizes conceituais e políticas. Belo Horizonte: PROEX/UFMG, 2000.

NOGUEIRA, Maria das Dores Pimentel. Extensão universitária no Brasil: uma revisão conceitual. In: FARIA, Dóris Santos de (org.). Construção conceitual da extensão na América Latina. Brasília: Editora UNB, 2001.

PAIXÃO, Marcelo. Manifesto anti-racista: ideias em prol de uma utopia chamada Brasil. Rio de Janeiro: DP\&A: LPP/ UERJ, 2006.

PAULA, João Antônio de. A extensão universitária: história, conceito e propostas. Interfaces: Revista de Extensão, Belo Horizonte, v. 1, n. 1, p. 5-23, jul./nov. 2013.

RAMOS, Marília Patta; SCHABBACH, Letícia Maria. O estado da arte da avaliação de políticas públicas: conceituação e exemplos de avaliação no Brasil. Revista de Administração Pública, Rio de Janeiro, v. 46, n. 5, p. 1271-1294, out. 2012. 
RÊSES, Erlando da Silva. E com a palavras: os alunos - estudo das representações sociais dos alunos da rede pública do Distrito Federal sobre a Sociologia no Ensino Médio. 2004. Dissertação (Mestrado em Sociologia) - Programa de Pós-Graduação em Sociologia, Universidade de Brasília, Brasília, DF, 2004.

SERRANO, Rossana Maria Souto Maior. Conceitos de extensão universitária: um diálogo com Paulo Freire. In: SEMINÁRIO NACIONAL DE PESQUISA EM EXTENSÃO POPULAR, 2., 2013, João Pessoa. Anais [...]. João Pessoa: UFPB, 2013.

THEODORO, Mário; DELGADO, Guilherme. Política social: universalização ou focalização - subsídios para o debate. Políticas sociais: acompanhamento e análise, Brasília, DF, n. 7, p. 122-126, ago. 2003.

UNIVERSIDADE DO ESTADO DO RIO DE JANEIRO (UERJ). Deliberação no 021. Rio de Janeiro, 2005. Disponível em: http://www.boluerj.uerj.br/pdf/de_00212005_28092005.pdf. Acesso em: 9 abr. 2020.

UNIVERSIDADE DO ESTADO DO RIO DE JANEIRO (UERJ). Projeto Político Pedagógico. Rio de Janeiro: CAp UERJ, 2013. Disponível em: http://www.cap.uerj.br/site/images/stories/noticias/projeto-politico-pedagogico-1.pdf. Acesso em: 20 abr. 2020 .

Data de submissão: 19/06/2020

Data de aceite: 05/08/2020 